\title{
Granisetron Augmentation of Sertraline in Obsessive-Compulsive Disorder: A Double-Blind Placebo-Controlled, Randomized Clinical Trial
}

\section{Ala Ghobadian}

Psychosocial Health Research Institute (PHRI), Iran University of Medical Sciences

\section{Saba Mokhtari}

University of Social Welfare and Rehabilitation

\section{Behnam Shariati}

Psychosocial Health Research Institute (PHRI), Iran University of Medical Sciences

\section{Leila Kamalzadeh}

Psychosocial Health Research Institute (PHRI), Iran University of Medical Sciences

\section{Mohsen Shati}

Iran University of Medical Sciences

\section{Mehrdad Eftekhar Ardebili}

Psychosocial Health Research Institute (PHRI), Iran University of Medical Sciences

\section{Masoomeh Yarahmadi}

Psychosocial Health Research Institute (PHRI), Iran University of Medical Sciences

\section{Mohammadreza Shalbafan ( $\sim$ Shalbafan.mr@iums.ac.ir)}

Psychosocial Health Research Institute (PHRI), Iran University of Medical Sciences

\section{Research Article}

Keywords: Serotonin 5-HT3 receptor, Obsessive-compulsive disorder, Randomized controlled trial, Selective serotonin reuptake inhibitors, Granisetron

Posted Date: January 12th, 2022

DOI: https://doi.org/10.21203/rs.3.rs-1135729/v1

License: (c) (i) This work is licensed under a Creative Commons Attribution 4.0 International License. Read Full License 


\section{Abstract}

Background: Medications currently recommended for the treatment of Obsessive-Compulsive Disorder (OCD) usually relieve the severity of symptoms by as much as $20-30 \%$, and satisfactory treatment is obtained in $40-60 \%$ of patients with OCD. Nevertheless, the remaining symptoms continue to impair the patients' function. Therefore, it is necessary to investigate possible strategies to improve the mitigation of symptoms.

In this study, the main objective was to examine and investigate the effectiveness of granisetron, which is a serotonin 5-hydroxytryptamine receptor type $3\left(5-\mathrm{HT}_{3}\right)$ antagonist, as an adjunct therapy to selective serotonin reuptake inhibitors, for the purpose of ameliorating OCD symptoms.

Methods: fifty-eight patients diagnosed with OCD, based on Diagnostic and Statistical Manual of Mental Disorders (DSM-5) criteria, who had a Yale-Brown obsessive-compulsive scale (Y-BOCS) score of more than 21 were recruited in a double-blinded, parallel-group, placebo-controlled, clinical trial of 10 weeks to receive either granisetron ( $1 \mathrm{mg}$ twice daily) and sertraline (100 mg daily initially followed by $200 \mathrm{mg}$ daily after week 4 ) or placebo and sertraline. The primary outcome was OCD symptoms measured by the Y-BOCS.

Results: Y-BOCS total score significantly dropped in both groups (28.9 to 17.7 for granisetron and 27.5 to 19.3 for placebo group with a slightly greater drop for granisetron group), while the granisetron group experienced a significantly greater reduction in obsession scores (Greenhouse-Geisser $F(2.32,97.57)=4.52$, $p$-value=0.01). Moreover, in comparison with the placebo group, the proportion of the patients showing complete response was considerably higher among the granisetron group ( $P$-value $<0.01)$. No major adverse effects were observed in any of the groups.

Conclusion: The results suggest that granisetron augmentation of sertraline may increase the rate of response in patients with moderate to severe non-refractory OCD. Further studies are suggested in this regard.

Trial registration: The trial was registered at the Iranian Registry of Clinical Trials on 27/03/2019 (www.irct.ir; IRCT ID: IRCT20170123032145N3).

\section{Background}

Obsessive-Compulsive Disorder (OCD) affects nearly $1-3 \%$ of the world population $(1,2)$. OCD is characterized by intrusive thoughts which cause discomfort, apprehension, and/or repetitive behaviors which try to reduce the associated anxiety(3). If left untreated, the illness trajectory is waxing and waning chronically (4). OCD severely impairs quality of life and causes impairment in social and occupational function in patients $(5,6)$. 
Currently, selective serotonin reuptake inhibitors (SSRIs) and/or cognitive behavioral therapy, particularly exposure and response prevention (ERP), are considered first-line treatments for $\operatorname{OCD}(7,8)$. SSRIs usually reduce the effect and severity of Obsessive-Compulsive Disorder symptoms by as much as $20-30 \%(9)$. Satisfactory treatment is obtained in $40-60 \%$ of patients with $\operatorname{OCD}(10,11)$. Nevertheless, the remaining symptoms continue to impair the patients' function. For patients who do not respond adequately to firstline treatments, combination therapy of CBT and SSRIs, pharmacological augmentation of SSRIs, and changing SSRIs to another drug (in case there is a specific SSRI resistance) used as second-line therapies(12).

Granisetron is a highly selective and potent $5-\mathrm{HT}_{3}$ receptor antagonist which has very little or no affinity for other receptors.(13). It is used to effectively prevent post-chemotherapy, post-radiotherapy, or postsurgery nausea and vomiting. Due to its high lipophilicity, granisetron is an ideal choice to pass the bloodbrain barrier and to be used in nervous system disorders(14).

The $5-\mathrm{HT}_{3}$ receptor antagonists, for instance, ondansetron and granisetron, have resulted positively in augmentation with SSRIs to decrease OCD-related symptoms in previous studies (15-17). Recent evidence suggests that ondansetron and tropisetron, other members of the $5-\mathrm{HT}_{3}$ receptor antagonist family, have been successfully used to treat $\operatorname{OCD}(12,16-18)$. So far, only two studies have attempted to investigate the efficacy of granisetron for the treatment of $\operatorname{OCD}(15,19)$. Overall, the results of these studies supported the potential efficacy and safety of $5-\mathrm{HT}_{3}$ receptor antagonists for the treatment of patients with OCD. No animal OCD models have directly implicated $5-\mathrm{HT}_{3}$ receptors. However, despite these studies and their results, the benefit of $5-\mathrm{HT}_{3}$ antagonists for $\mathrm{OCD}$ are not yet totally conclusive (18).

Recent research has shown the important role of disgust in the symptoms of the obsessive-compulsive disorder (OCD). Excessive disgust reactions may cause some of the symptoms of OCD, and in many cases, can even overshadow the anxiety symptoms(20). One of the models of the pathology of nausea is based on conditioned and learned disgust (21) and some studies showed the superiority of this hypothesis on rats (22), so the use of antiemetics can be supported by these models in treating the obsessive-compulsive disorder.

One of the important adverse effects of serotonin reuptake inhibitors (SSRIs) is nausea and it can reduce compliance to medication. Using 5-HT3 blockers, as augmentation therapy is preferred choice especially in cases of drug-induced nausea(23). Given the need to find new options to increase OCD patients' treatment responsiveness, this study aimed to investigate the additional benefits of granisetron augmentation therapy with sertraline in OCD symptom reduction compared to sertraline alone.

\section{Methods}

Trial setting and design 
A 10-week, double-blind, randomized, placebo-controlled, parallel-group trial was performed at the outpatient clinics of Iran Psychiatric Hospital and Tehran Psychiatric Institute (affiliated with Iran University of Medical Sciences, Tehran, Iran) from April to December 2019.

\section{Participants}

Patients, aged 18-60 years, with a clinical diagnosis of OCD based on DSM-5 criteria, were screened for the study(24). Those with a diagnosis of moderate-to-severe OCD, defined by a Yale-Brown Obsessive Compulsive Scale (Y-BOCS) score of $\geq 21$ were included $(25,26)$.

The patients attending the clinics were consecutively checked for the entry criteria and recruited until the sample size was achieved. All of the patients enrolled in the study were assessed with a structured clinical interview designed in accordance with the DSM-5 by an expert psychiatrist(24).

The exclusion criteria were: 1 ) the presence of life-threatening psychiatric symptoms (such as suicidal ideation); 2) comorbid axis I disorders; 3) serious medical or neurological conditions; 4) substance dependence (other than caffeine or nicotine); 5) intellectual disability (based on clinical judgment); 6) pregnancy/breastfeeding; 7) contraindication for the use of granisetron or sertraline; 8) history of the previous psychosurgery for OCD; 9 ) have a complete response with sertraline in their history. During the conduction of the trial, patients were not permitted to participate in any psychotherapeutic treatment. Furthermore, patients were excluded if they used any psychotropic drugs in the last 6 weeks $(11,12)$.

Interventions

Eligible participants were randomized to receive either granisetron, $1 \mathrm{mg}$ twice per day, or placebo for 10 weeks. All participants, regardless of group assignment, also received sertraline, $100 \mathrm{mg} /$ day for 4 weeks, and then gradually increased to $200 \mathrm{mg} /$ day. To minimize the side effects to the lowest level, the dosage of sertraline increased slowly every week.

\section{Outcome}

Y-BOCS was used for the assessment of patients at baseline and at weeks $0,4,8$, and 10 of therapy. YBOCS provides a rating scale for the severity of obsessive-compulsive symptoms $(11,12)$. This clinicianrated scale contains 10 questions, each item rated from 0 (no symptoms) to 4 (extreme symptoms)(26). The psychometric properties of the Persian version of Y-BOCS are approved in previous studies(27-29).

The primary outcome of the trial was the difference of total score of the Y-BOCS among the two groups and between the baseline and the end of the trial. The secondary outcome measure was Y-BOCS compulsion and obsession subscale score changes between two groups during the trial period, and also the complete response, partial response, and remission rates, defined as $\geqslant 35 \%, \geqslant 25 \%$ decrease in, and $\leqslant 16$ Y-BOCS total scores (30). Moreover, adverse effects were monitored every four weeks using a systematic questionnaire and three open questions to include any other side effects not included in the questionnaire (31-33). In case of observation of any serious adverse effects during the course of therapy, 
a physician assessed the potential role of the medication in inducing the adverse effects and omitted the patient from the trial. All missing outcome data have been imputed and did not include in the analysis.

Randomization, allocation, concealment, and blinding

Randomization of participants was conducted with a random permuted block method (ratio of 1:1 and blocks of four). The assigned group of each participant was printed consecutively and enveloped in similar in appearance. The allocation was not in reach of the participants or any outcome assessors. The statistical analyzer, randomizer, and outcome assessor each were separate individuals and were blinded to allocation. Also, granisetron and placebo tablets were similar in shape, color, size, and odor.

Sample size and statistical analysis

With a between-group difference of five points in Y-BOCS score, type I error of $5 \%$, an effect size of 0.25 , and power of $80 \%$, using G-power 3.1.9.2 we calculated a sample size of 44 (22 in each group).

Considering a drop-out rate of $30 \%(11,12)$, our final sample size was calculated at 58 (29 in each group). IBM SPSS Statistic 23.0.0 (IBM Corporations, Somers, New York, USA) was used for the statistical analysis. Continuous variables were reported as mean \pm SD and categorical variables as $\mathrm{n}(\%)$. Mean differences (MDs) between groups were reported as MDs (95\% confidence interval (Cl)). Fisher's exact test, or $\chi 2$-test was used for the comparison among categorical variables. The independent samples t-test was conducted for the comparison of continuous variable values, respectively. The comparison of $Y$ BOCS total and subscale score changes in and between groups during the ten-week course of study was achieved by performing a two-factor, repeated-measure analysis of variance (ANOVA). Whenever sphericity of the data could not be assumed using the Mauchly's test of sphericity, the GreenhouseGeisser correction for degrees of freedom was used. Score changes from baseline in the participants of each group was examined using the paired sample t-test. A p-value level of $\leqslant 0.05$ was defined as significant. Missing data was imputed with last observation carried forward (LOCF) method.

\section{Results}

\section{Participants}

One hundred and eight patients were screened primarily, while 58 patients were recruited (randomly assigned to groups of granisetron+sertraline or placebo+sertraline), and 45 patients completed the trial. The rial flow diagram and causes of dropouts are represented in Figure 1. In the first 4weeks there were 27 patients in the granistron group and 21 patients in the placebo group that the Baseline characteristics are summarized for each group separately in Table 1. 
Table 1

Baseline characteristics of participants

\begin{tabular}{|c|c|c|c|c|c|c|}
\hline & & Treatment Gr & & & & P- \\
\hline & & $\begin{array}{l}\text { granisetronts } \\
(n=27)\end{array}$ & rtraline & $\begin{array}{l}\text { placebo+ser } \\
(\mathrm{n}=21)\end{array}$ & aline & \\
\hline & & Mean士SD & $\begin{array}{l}\text { Count } \\
(\%)\end{array}$ & Mean士SD & $\begin{array}{l}\text { Count } \\
(\%)\end{array}$ & \\
\hline Age (years) & & $35.48 \pm 10.97$ & & $33.44 \pm 9.35$ & & 0.49 \\
\hline Duration of dis & (years) & $2.33 \pm 3.48$ & & $3.44 \pm 5.05$ & & 0.37 \\
\hline Gender & Female & & $\begin{array}{l}20 \\
(74.1 \%)\end{array}$ & & $\begin{array}{l}13 \\
(61.9 \%)\end{array}$ & 0.53 \\
\hline & Male & & $\begin{array}{l}7 \\
(25.9 \%)\end{array}$ & & $\begin{array}{l}8 \\
(38.1 \%)\end{array}$ & \\
\hline Education & Illiterate & & $1(3.7 \%)$ & & $\begin{array}{l}0 \\
(0.0 \%)\end{array}$ & 0.21 \\
\hline & Primary & & $0(0.0 \%)$ & & $\begin{array}{l}1 \\
(4.8 \%)\end{array}$ & \\
\hline & Secondary & & $2(7.4 \%)$ & & $\begin{array}{l}1 \\
(4.8 \%)\end{array}$ & \\
\hline & $\begin{array}{l}\text { High school } \\
\text { diploma }\end{array}$ & & $1(3.7 \%)$ & & $\begin{array}{l}5 \\
(23.8 \%)\end{array}$ & \\
\hline & $\begin{array}{l}\text { University } \\
\text { Education }\end{array}$ & & $\begin{array}{l}23 \\
(85.2 \%\end{array}$ & & $\begin{array}{l}14 \\
(66.7 \%)\end{array}$ & \\
\hline Marital status & Single & & $\begin{array}{l}16 \\
(59.3 \%)\end{array}$ & & $\begin{array}{l}13 \\
(61.9 \%)\end{array}$ & 1 \\
\hline & Married & & $\begin{array}{l}11 \\
(40.7 \%)\end{array}$ & & $\begin{array}{l}8 \\
(38.1 \%)\end{array}$ & \\
\hline Employment & Employed & & $\begin{array}{l}15 \\
(55.6 \%)\end{array}$ & & $\begin{array}{l}10 \\
(47.6 \%)\end{array}$ & 0.46 \\
\hline & Unemployed & & $\begin{array}{l}7 \\
(25.9 \%)\end{array}$ & & $\begin{array}{l}3 \\
(14.3 \%)\end{array}$ & \\
\hline & Housewife & & $\begin{array}{l}5 \\
(18.5 \%)\end{array}$ & & $\begin{array}{l}5 \\
(23.8 \%)\end{array}$ & \\
\hline & Student & & $0(0.0 \%)$ & & $\begin{array}{l}3 \\
(14.3 \%)\end{array}$ & \\
\hline $\begin{array}{l}\text { Previous } \\
\text { treatment }\end{array}$ & Yes & & $\begin{array}{l}12 \\
(44.4 \%)\end{array}$ & & $\begin{array}{l}12 \\
(57.1 \%)\end{array}$ & 0.56 \\
\hline
\end{tabular}




\begin{tabular}{|c|c|c|c|c|c|c|}
\hline & & \multicolumn{4}{|c|}{ Treatment Group } & \multirow{3}{*}{$\begin{array}{l}\mathrm{P}- \\
\text { value }\end{array}$} \\
\hline & & \multicolumn{2}{|c|}{$\begin{array}{l}\text { granisetron+sertraline } \\
(\mathrm{n}=27)\end{array}$} & \multicolumn{2}{|c|}{$\begin{array}{l}\text { placebo+sertraline } \\
(n=21)\end{array}$} & \\
\hline & & Mean $\pm S D$ & $\begin{array}{l}\text { Count } \\
\text { (\%) }\end{array}$ & Mean $\pm S D$ & $\begin{array}{l}\text { Count } \\
\text { (\%) }\end{array}$ & \\
\hline & No & & $\begin{array}{l}15 \\
(55.6 \%)\end{array}$ & & $\begin{array}{l}9 \\
(42.9 \%)\end{array}$ & \\
\hline \multirow{3}{*}{$\begin{array}{l}\text { Y-BOCS score } \\
\text { (week 0) }\end{array}$} & Total & $28.92 \pm 7.15$ & & $27.5 \pm 4.95$ & & 0.44 \\
\hline & Obsession & $16.62 \pm 3.04$ & & $14.75 \pm 3.79$ & & 0.06 \\
\hline & Compulsion & $12.48 \pm 5.41$ & & $12.5 \pm 3.2$ & & 0.98 \\
\hline
\end{tabular}

Y-BOCS total score.

The baseline Y-BOCS total score was not significantly different between the groups $(\mathrm{MD}(95 \% \mathrm{Cl})=$ 1.4(-2.26-5.10), $p$-value $=0.442$, Table 1). Total Y-BOCS score changes from baseline in the granisetron group at fourth and tenth week of the study was MD $(95 \% \mathrm{Cl})=5.6(1.21-9.98)(\mathrm{p}$-value $<0.01)$ at week 4 and $\mathrm{MD}(95 \% \mathrm{Cl})=11.2(6.65-15.74)(\mathrm{p}$-value $<0.01)$ at tenth week, respectively. Similarly, participants in the placebo group experienced significant Y-BOCS total score drop at 10 weeks into the trial, while their score change mean differences were MD $(95 \% \mathrm{Cl})=8.4(4.78-12.01)(p-v a l u e<0.01)$ but in the 4 th week the change in the placebo group was not significant $(\mathrm{MD}(95 \% \mathrm{Cl})=2.9(0.68-6.48)(\mathrm{p}$-value $=0.1))$ in the end, Repeated measures ANOVA revealed no significant difference for the time between granisetron and placebo groups (Greenhouse-Geisser $F(2.240,96.307)=2.31$, p-value<0.09). (figure 2) (Table 2).

Until the end of the study, 14 (70\%) participants in the placebo group and $20(80 \%)$ participants of the granisetron group fulfilled the criteria for a partial response which doesn't have a significant difference ( $p$ value $=0.43$ ) Also, Ten-week remission rates don't significantly differ between granisetron and placebo groups with $15(60 \%)$ participants from the granisetron group and 7 (35\%) participants from the placebo group ( $p$-value=0.09); But in the tenth week, 20 (80\%) participants among the granisetron group and 8 (40\%) participants in the placebo group were complete responders which shows a significant difference between two groups ( $p$-value< 0.01 ).

Y-BOCS obsession subscale score.

The baseline Y-BOCS obsession subscale score did not significantly differ among treatment groups (MD $(95 \% \mathrm{Cl})=1.87(-0.11-3.85), \mathrm{p}$-value $=0.06($ Table 1$))$. Obsession Y-BOCS score changes from baseline in the granisetron group at fourth and tenth week of the study was MD $(95 \% \mathrm{Cl})=3.92(1.86-5.97)(\mathrm{p}-$ value $<0.01)$ at week 4 and $\mathrm{MD}(95 \% \mathrm{Cl})=7.62(5.40-9.83)(\mathrm{p}$-value $<0.01)$ at tenth week, respectively. Similarly, participants in the placebo group experienced significant Y-BOCS total score drop at 10 weeks into the trial, while their score change mean differences were MD $(95 \% \mathrm{Cl})=4.7(2.39-7.00)(p$-value 
$<0.01)$ but in the 4th week the change in the placebo group was not significant (MD $(95 \% \mathrm{Cl})=1.75$ $(-0.71-4.21)$ ( $p$-value 0.15$)$ ). The timextreatment group interaction analysis by repeated-measures ANOVA revealed that granisetron group participants significantly experienced higher Y-BOCS obsession subscale score decrease (Greenhouse-Geisser $F(2.32,97.57)=4.52, p$-value $=0.01$ ) (Table 2). The Y-BOCS obsession subscale score change trend for each group is presented in Figure 3.

Y-BOCS compulsion subscale score.

The baseline Y-BOCS compulsion subscale score did not significantly differ among treatment groups $(\mathrm{MD}(95 \% \mathrm{Cl})=-0.02(-2.7-2.66), \mathrm{p}$-value=0.98 (Table1)). Compulsion Y-BOCS score changes from baseline in the granisetron group at tenth week of the study was $\mathrm{MD}(95 \% \mathrm{Cl})=3.64(0.73-6.54)$ ( $\mathrm{p}$-value 0.01) and placebo group experienced significant Y-BOCS total score drop at 10 weeks into the trial, respectively $(\mathrm{MD}(95 \% \mathrm{Cl})=3.45(1.22-5.67)(\mathrm{p}$-value $<0.01))$ but both groups have no significant change in the 4th week and the timextreatment group interaction analysis by repeated-measures ANOVA revealed no significant difference (Greenhouse-Geisser $F(2.13,91.97)=0.315$, $p$-value $=0.74$ ) (Table 2). The Y-BOCS compulsion subscale score change trend for each group is presented in Figure 4

Adverse effects

Adverse events were recorded during the study. Side effects were mild and did not result in withdrawal. The frequency of side effects was not different between the two groups (Table 3). 
Table 2

Comparison of Yale-Brown obsessive-compulsive scale (Y-BOCS) subscales score change from baseline for treatment groups

\begin{tabular}{|c|c|c|c|c|c|c|c|}
\hline \multirow{2}{*}{\multicolumn{2}{|c|}{$\begin{array}{l}\text { Y-BOCS subscale score } \\
\text { reduction }\end{array}$}} & \multicolumn{6}{|c|}{ Treatment group } \\
\hline & & \multicolumn{3}{|c|}{ granisetron+sertraline } & \multicolumn{3}{|c|}{ placebo+sertraline } \\
\hline & & Mean $\pm S D$ & $\begin{array}{l}\mathrm{MD}(95 \% \\
\mathrm{Cl})\end{array}$ & $\begin{array}{l}\mathrm{p}- \\
\text { Value }\end{array}$ & Mean $\pm S D$ & $\begin{array}{l}\mathrm{MD} \\
(95 \% \mathrm{Cl})\end{array}$ & $\begin{array}{l}\mathrm{p}- \\
\text { Value }\end{array}$ \\
\hline \multirow[t]{4}{*}{ Obsession } & \multirow[t]{2}{*}{ Week 4} & \multirow[t]{2}{*}{$12.7 \pm 4.36$} & 3.92 & \multirow[t]{2}{*}{0.0003} & \multirow[t]{2}{*}{$13 \pm 4.11$} & 1.75 & \multirow[t]{2}{*}{0.15} \\
\hline & & & $(1.86-5.97)$ & & & $\begin{array}{l}(-0.71- \\
4.21)\end{array}$ & \\
\hline & Week 8 & $10.41 \pm 4.4$ & $\begin{array}{l}6.21(4.14- \\
8.27)\end{array}$ & 0.0001 & $11.45 \pm 3.66$ & $\begin{array}{l}3.3 \\
(0.97- \\
5.62)\end{array}$ & 0.006 \\
\hline & $\begin{array}{l}\text { Week } \\
10\end{array}$ & $9 \pm 4.87$ & $\begin{array}{l}7.62 \\
(5.40-9.83)\end{array}$ & 0.0001 & $10.05 \pm 3.6$ & $\begin{array}{l}4.7 \\
(2.39- \\
7.00)\end{array}$ & 0.0002 \\
\hline \multirow[t]{5}{*}{ Compulsion } & \multirow[t]{2}{*}{ Week 4} & \multirow[t]{2}{*}{$10.8 \pm 5.15$} & 1.68 & \multirow[t]{2}{*}{0.24} & \multirow[t]{2}{*}{$11.55 \pm 3.8$} & 0.95 & \multirow[t]{2}{*}{0.38} \\
\hline & & & $(-1.20-4.56)$ & & & $\begin{array}{l}(-1.24- \\
3.14)\end{array}$ & \\
\hline & Week 8 & $4.93 \pm 4.86$ & $\begin{array}{l}3.16(0.35- \\
5.96)\end{array}$ & 0.02 & $9.45 \pm 3.84$ & $\begin{array}{l}3.05 \\
(0.84- \\
5.25)\end{array}$ & 0.007 \\
\hline & \multirow{2}{*}{$\begin{array}{l}\text { Week } \\
10\end{array}$} & \multirow[t]{2}{*}{$8.84 \pm 5.21$} & 3.64 & \multirow[t]{2}{*}{0.01} & \multirow[t]{2}{*}{$9.05 \pm 3.91$} & 3.45 & \multirow[t]{2}{*}{0.003} \\
\hline & & & $(0.73-6.54)$ & & & $\begin{array}{l}(1.22- \\
5.67)\end{array}$ & \\
\hline \multirow[t]{3}{*}{ Total } & Week 4 & $23.32 \pm 8.83$ & $\begin{array}{l}5.6(1.21- \\
9.98)\end{array}$ & 0.013 & $24.6 \pm 6.42$ & $\begin{array}{l}2.9 \\
(-0.68- \\
6.48)\end{array}$ & 0.10 \\
\hline & Week 8 & $19.6 \pm 8.55$ & $\begin{array}{l}9.32(5.01- \\
13.62)\end{array}$ & 0.0001 & $20.9 \pm 6.19$ & $\begin{array}{l}6.6 \\
(3.09- \\
10.10)\end{array}$ & 0.0005 \\
\hline & $\begin{array}{l}\text { Week } \\
10\end{array}$ & $17.72 \pm 9.34$ & $\begin{array}{l}11.2(6.65- \\
15.74)\end{array}$ & 0.0001 & $19.1 \pm 6.51$ & $\begin{array}{l}8.4 \\
(4.78- \\
12.01)\end{array}$ & 0.001 \\
\hline
\end{tabular}


Table 3

Frequency of adverse events in the two groups

\begin{tabular}{|c|c|c|c|c|c|}
\hline \multirow[t]{3}{*}{ Adverse events } & \multicolumn{5}{|c|}{ Treatment group } \\
\hline & \multicolumn{2}{|c|}{ granisetron+sertraline } & \multicolumn{2}{|c|}{ placebo+sertraline } & \multirow[t]{2}{*}{$p$-value } \\
\hline & $\mathrm{N}$ & $\%$ & $\mathrm{~N}$ & $\%$ & \\
\hline Muscle pain & 1 & 3.7 & 0 & 0 & 0.99 \\
\hline Headache & 1 & 3.7 & 0 & 0 & 0.99 \\
\hline Diarhea & 0 & 0 & 1 & 4.8 & 0.43 \\
\hline Constipation & 1 & 3.7 & 0 & 0 & 0.99 \\
\hline Decreased libido & 3 & 11.1 & 1 & 4.8 & 0.62 \\
\hline Decreased appetite & 1 & 3.7 & 0 & 0 & 0.99 \\
\hline Lightheadness & 1 & 3.7 & 1 & 4.8 & 0.99 \\
\hline Tremor & 1 & 0 & 0 & 0 & 0.99 \\
\hline Skin lesions & 1 & 0 & 0 & 0 & 0.99 \\
\hline Motor tic & 0 & 0 & 1 & 4.8 & 0.43 \\
\hline Palpitation & 1 & 3.7 & 0 & 0 & 0.99 \\
\hline Insomnia & 2 & 7.4 & 1 & 4.8 & 0.99 \\
\hline Itching & 0 & 0 & 1 & 4.8 & 0.43 \\
\hline Restlesness & 0 & 0 & 1 & 4.8 & 0.43 \\
\hline Vomiting & 1 & 3.7 & 0 & 0 & 0.99 \\
\hline
\end{tabular}

\section{Discussion}

The results showed a greater reduction in Y-BOCS total score, as well as, its subscales in patients treated by granisetron plus sertraline in comparison with placebo plus sertraline. However, this difference was statistically significant only for the obsession subscale. Furthermore, our trial showed more partial responses, complete responses, and remission rates among patients receiving granisetron in comparison with placebo. Despite the difference in remission rates between the two groups (60\% in the granisetron arm, and $35 \%$ in the placebo arm), the only difference in the complete response rate was statistically significant. This result may be explained by the small sample size of our study. Interestingly, our study showed that the rate of observed side effects was not significantly different between the granisetron and placebo groups. 
The inclusion of OCD patients scoring at least 21 at the Y-BOCS (that consider as moderate to severe) may have driven the absolute score reduction in both arms and caused an insignificant difference between the two groups, thus there is a good difference in scores at the study endpoint between the two groups ( 17.7 for the granisetron and 19.1 for the placebo group)

The findings of our study are in agreement with previous trials and our hypothesis which stated granisetron is an effective and well-tolerated agent to be used as adjuvant therapy to SSRIs for the treatment of OCD. To the best of our knowledge, the current study is the first 10-week double-blind randomized placebo-controlled trial to investigate the efficacy and safety of granisetron as adjuvant therapy to sertraline for moderate to severe OCD. In a recent study, Askari et al. reported that granisetron augmentation of fluvoxamine results in a greater reduction in OCD symptoms compared to a placebo(15). They also reported significantly higher remission and complete response rates among patients in the granisetron group(15). Our findings are in agreement with their report. Similar to our results, Askari et al. reported the safety and well-tolerability of granisetron plus fluvoxamine in comparison with placebo plus fluvoxamine(15). However, we believe that our trial has some strengths in comparison with their trial. The key strengths of the present study are its larger sample size and longer duration of follow-up. Moreover, we used sertraline as a standard treatment of OCD for both granisetron and placebo groups. It is well-known that sertraline has the lowest drug-drug interaction among SSRIs approved for the treatment of $\mathrm{OCD}(34)$, and it seems to be the best option for adjuvant therapy. In the same vein, Sharafkhani et al. (2019) reported the efficacy of granisetron in patients with treatmentresistant $O C D$ in a 14-week trial in comparison with the ondansetron arm and placebo arm. Although they reported the efficacy of granisetron in the treatment of the patients, they concluded that ondansetron is a superior option to granisetron(19). The results of their study are hardly comparable to ours because the present study was performed on patients with moderate to severe $O C D$, not treatment-resistant patients.

Although the evidence presented thus far supports the efficacy and safety of $5 \mathrm{HT}_{3}$ receptor antagonists such as ondansetron and tropisetron in the treatment of $\operatorname{OCD}$ patients $(12,16,17)$, a recent systematic review concluded that more clinical trials are needed to confirm the efficacy of these agents as treatment options for $\mathrm{OCD}(18)$.

The exact mechanism of $5 \mathrm{HT}_{3}$ receptor antagonists in the treatment of OCD symptoms is not yet wellknown. Some researchers have reported that the $5 \mathrm{HT}_{3}$ antagonists may ameliorate dopamine hyperactivity in ventral tegmental area in animal models(35), which is one of the known dysregulated systems in OCD, more specifically, due to its importance in reward circuity(36). Another possible mechanism underlying the efficacy of $5 \mathrm{HT}_{3}$ antagonists in the treatment of $\mathrm{OCD}$ is the amelioration of dopaminergic activity in the prefrontal areas by these agents, given the fact that high levels of $5 \mathrm{HT}_{3}$ receptors are located in the prefrontal cortex, amygdala and hippocampus $(37,38)$. The efficacy of dopamine antagonists in the treatment of OCD, which has been shown in previous studies, supports this hypothesis as well $(39,40)$. 
On the other hand, $5 \mathrm{HT}_{3}$ antagonists modulate the glutamatergic system through $\mathrm{N}$-methyl $\mathrm{d}$ - aspartate (NMDA) receptor antagonism. Recently, augmentation strategies using glutamatergic agents has been explored in patients with OCD and the efficacy of these agents have been confirmed in several trials (11, $27,41)$.

\section{Limitations}

Finally, some important limitations need to be considered. First, a 10week trial for following up OCD patients is a little short and a longer study is suggested. As we thought that the inclusion of moderate to severe OCD patients may have driven the absolute score reduction in both arms and caused an insignificant difference between the two groups, performing other similar studies on patients with less $Y$ BOCS scores can be valuable. We also defined the complete response, partial response, and remission rates, as $\geqslant 35 \%, \geqslant 25 \%$ decrease in, and $\leqslant 16$ Y-BOCS total scores which in some other studies it defines with greater response and using that can affect the results. Additionally, our study was not performed on treatment-resistant OCD patients and the findings cannot be generalized to this population.

\section{Conclusion}

Taken together, these results suggest that granisetron augmentation of sertraline may increase the rate of response in patients with moderate to severe non-refractory $\mathrm{OCD}$. Further studies are suggested in this regard. There is abundant room for further progress in determining the exact mechanism of action of granisetron in the treatment of OCD.

\section{Abbreviations}

Obsessive-Compulsive Disorder

OCD

N-Methyl-D-aspartate

NMDA

selective serotonin reuptake inhibitor

SSRI

Diagnostic and Statistical Manual of Mental Disorders

DSM-5

Yale-Brown obsessive compulsive scale

Y-BOCS

exposure and response prevention

ERP

5-hydroxytryptamine receptor type 3

$5-\mathrm{HT}_{3}$

analysis of variance

ANOVA 
last observation carried forward

LOCF

Mean difference

MD

confidence interval

$\mathrm{Cl}$

standard deviation

SD

\section{Declarations}

Funding: The authors disclose receipt of the following financial support for the research, authorship, and/or publication of this article: This study was funded by Iran University of Medical Sciences (Grant no: 97-4-23-13222).

\section{Ethics approval and consent to participate}

The trial was approved by the ethics committee of Iran University of Medical Sciences institutional review board (IRB: IR.IUMS.REC.1398.060, grant number: 97-4-23-13222) and conducted according to the Declaration of Helsinki and subsequent revisions. Written informed consent was obtained from all participants. Patients were informed that the nature of their participation was a voluntary activity and that they had the right to leave the trial at any time with no negative effect regarding their treatment. The trial was registered at the Iranian Registry of Clinical Trials (www.irct.ir; IRCT ID:

IRCT20170123032145N3).

\section{Consent for publication}

Not applicable

\section{Availability of data and materials}

The datasets generated and/or analysed during the current study are not publicly available due to confidentiality concerns (in the informed consent, we have made a commitment to the participants to publish only the general and group results of the study) but are available from the corresponding author on reasonable request.

\section{Competing interests}

The authors have no conflicts of interest to report.

\section{Funding}

The authors disclose receipt of the following financial support for the research, authorship, and/or publication of this article: This study was funded by Iran University of Medical Sciences (Grant no: 97-4- 
23-13222).

\section{Authors' contributions}

AG, BS, LK, MEA and MS made substantial contributions to the conception and design of the work. AG, $B S, M Y$ and MS have substantial contribution in data gathering. SM and MS analyzed and interpreted the data. AG, SM, LK and MS have major contribution in writing the manuscript. All authors read and approved the final manuscript.

\section{Acknowledgement}

This study was Dr. Ala Ghobadian's postgraduate thesis toward the Iranian Board of Psychiatry.

\section{References}

1. Karno M, Golding JM, Sorenson SB, Burnam MA. The epidemiology of obsessive-compulsive disorder in five US communities. Archives of general psychiatry. 1988;45(12):1094-9.

2. Sasson Y, Zohar J, Chopra M, Lustig M, lancu I, Hendler T. Epidemiology of obsessive-compulsive disorder: A world view. The Journal of clinical psychiatry. 1997.

3. Hirschtritt ME, Bloch MH, Mathews CA. Obsessive-compulsive disorder: advances in diagnosis and treatment. Jama. 2017;317(13):1358-67.

4. Thomsen PH. Obsessive-compulsive disorders. European child \& adolescent psychiatry. 2013;22(1):23-8.

5. Albert U, Maina G, Bogetto F, Chiarle A, Mataix-Cols D. Clinical predictors of health-related quality of life in obsessive-compulsive disorder. Comprehensive psychiatry. 2010;51(2):193-200.

6. DuPont RL, Rice D, Shiraki S, Rowland C. Economic costs of obsessive-compulsive disorder. Medical interface. 1995;8(4):102-9.

7. Seibell PJ, Hollander E. Management of obsessive-compulsive disorder. F1000prime reports. 2014;6.

8. Foa EB, Liebowitz MR, Kozak MJ, Davies S, Campeas R, Franklin ME, et al. Randomized, placebocontrolled trial of exposure and ritual prevention, clomipramine, and their combination in the treatment of obsessive-compulsive disorder. American Journal of psychiatry. 2005;162(1):151-61.

9. Pigott TA, Seay SM. A review of the efficacy of selective serotonin reuptake inhibitors in obsessivecompulsive disorder. The Journal of clinical psychiatry. 1999.

10. Erzegovesi S, Cavallini MC, Cavedini P, Diaferia G, Locatelli M, Bellodi L. Clinical predictors of drug response in obsessive-compulsive disorder. Journal of clinical psychopharmacology. 2001;21(5):488-92.

11. Arabzadeh S, Shahhossenie M, Mesgarpour B, Rezaei F, Shalbafan MR, Ghiasi Z, et al. L-carnosine as an adjuvant to fluvoxamine in treatment of obsessive compulsive disorder: A randomized doubleblind study. Human Psychopharmacology: Clinical and Experimental. 2017;32(4):e2584. 
12. Shalbafan M, Malekpour F, Tadayon Najafabadi B, Ghamari K, Dastgheib S-A, Mowla A, et al. Fluvoxamine combination therapy with tropisetron for obsessive-compulsive disorder patients: A placebo-controlled, randomized clinical trial. Journal of Psychopharmacology. 2019;33(11):140714.

13. Aapro M. Granisetron: an update on its clinical use in the management of nausea and vomiting. The oncologist. 2004;9(6):673-86.

14. Machu TK. Therapeutics of 5-HT3 receptor antagonists: current uses and future directions. Pharmacology \& therapeutics. 2011;130(3):338-47.

15. Askari N, Moin M, Sanati M, Tajdini M, Modabbernia A, Najand B, et al. Granisetron Adjunct to Fluvoxamine for Moderate to Severe Obsessive-Compulsive Disorder. CNS drugs. 2012;26(10):88392.

16. Heidari M, Zarei M, Hosseini SM, Taghvaei R, Maleki $H$, Tabrizi M, et al. Ondansetron or placebo in the augmentation of fluvoxamine response over 8 weeks in obsessive-compulsive disorder. International clinical psychopharmacology. 2014;29(6):344-50.

17. Pallanti S, Bernardi S, Antonini S, Singh N, Hollander E. Ondansetron augmentation in patients with obsessive-compulsive disorder who are inadequate responders to serotonin reuptake inhibitors: improvement with treatment and worsening following discontinuation. European Neuropsychopharmacology. 2014;24(3):375-80.

18. Serata D, Kotzalidis GD, Rapinesi C, Janiri D, Di Pietro S, Callovini G, et al. Are 5-HT3 antagonists effective in obsessive-compulsive disorder? A systematic review of literature. Human Psychopharmacology: Clinical and Experimental. 2015;30(2):70-84.

19. Sharafkhah M, Aghakarim Alamdar M, Massoudifar A, Abdolrazaghnejad A, Ebrahimi-Monfared M, Saber $\mathrm{R}$, et al. Comparing the efficacy of ondansetron and granisetron augmentation in treatmentresistant obsessive-compulsive disorder: a randomized double-blind placebo-controlled study. Int Clin Psychopharmacol. 2019 Sep;34(5):222-33. PubMed PMID: 31058716. Epub 2019/05/07. eng.

20. Bhikram T, Abi-Jaoude E, Sandor P. OCD: obsessive-compulsive... disgust? The role of disgust in obsessive-compulsive disorder. Journal of psychiatry \& neuroscience: JPN. 2017;42(5):300.

21. Andrews PL, Sanger GJ. Nausea and the quest for the perfect anti-emetic. European journal of pharmacology. 2014;722:108-21.

22. Tuerke KJ, Limebeer CL, Fletcher PJ, Parker LA. Double dissociation between regulation of conditioned disgust and taste avoidance by serotonin availability at the 5-HT3 receptor in the posterior and anterior insular cortex. Journal of Neuroscience. 2012;32(40):13709-17.

23. Fornaro M, Martino M. Adding 5-hydroxytryptamine receptor type 3 antagonists may reduce druginduced nausea in poor insight obsessive-compulsive patients taking off-label doses of selective serotonin reuptake inhibitors: a 52-week follow-up case report. Annals of general psychiatry. 2010;9(1):39.

24. American Psychiatric Association Diagnostic and statistical manual of mental disorders 5th ed2013. 
25. Goodman WK, Price LH, Rasmussen SA, Mazure C, Delgado P, Heninger GR, et al. The yale-brown obsessive compulsive scale: II. Validity. Archives of general psychiatry. 1989;46(11):1012-6.

26. Goodman WK, Price LH, Rasmussen SA, Mazure C, Fleischmann RL, Hill CL, et al. The Yale-Brown obsessive compulsive scale: I. Development, use, and reliability. Archives of general psychiatry. 1989;46(11):1006-11.

27. Esalatmanesh S, Abrishami Z, Zeinoddini A, Rahiminejad F, Sadeghi M, Najarzadegan MR, et al. Minocycline combination therapy with fluvoxamine in moderate-to-severe obsessive-compulsive disorder: A placebo-controlled, double-blind, randomized trial. Psychiatry and clinical neurosciences. 2016;70(11):517-26.

28. Yousefzadeh F, Sahebolzamani E, Sadri A, Mortezaei A, Aqamolaei A, Mortazavi SH, et al. 5Hydroxytryptophan as adjuvant therapy in treatment of moderate to severe obsessive-compulsive disorder: a double-blind randomized trial with placebo control. International Clinical Psychopharmacology. 2020.

29. Shalbafan M, Mohammadinejad P, Shariat S-V, Alavi K, Zeinoddini A, Salehi M, et al. Celecoxib as an adjuvant to fluvoxamine in moderate to severe obsessive-compulsive disorder: A double-blind, placebo-controlled, randomized trial. Pharmacopsychiatry. 2015;48(4-5):136-40.

30. Pallanti S, Quercioli L. Treatment-refractory obsessive-compulsive disorder: methodological issues, operational definitions and therapeutic lines. Progress in Neuro-Psychopharmacology and Biological Psychiatry. 2006;30(3):400-12.

31. Ghajar A, Khoaie-Ardakani M-R, Shahmoradi Z, Alavi A-R, Afarideh M, Shalbafan M-R, et al. Lcarnosine as an add-on to risperidone for treatment of negative symptoms in patients with stable schizophrenia: A double-blind, randomized placebo-controlled trial. Psychiatry Research. 2018;262:94-101.

32. Araminia B, Shalbafan M, Mortezaei A, Shirazi E, Ghaffari S, Sahebolzamani E, et al. L-Carnosine combination therapy for major depressive disorder: A randomized, double-blind, placebo-controlled trial. Journal of Affective Disorders. 2020;267:131-6.

33. Ghaffari S, Ghobadi A, Jamshidi AH, Mortazavi SH, Naderi S, Aqamolaei A, et al. Cinnamomum tamala as an adjuvant therapy in the treatment of major depressive disorder: A double-blind, randomized, placebo-controlled clinical trial with placebo control. Advances in Integrative Medicine. 2019.

34. Mohseni-Bandpey R, Moradi Chemeh F, Shalbafan M. Myoclonus as a Single Side Effect of Combination of Selective Serotonin Reuptake Inhibitors (SSRIs) and Clomipramine: Three Case Reports. Journal of Mazandaran University of Medical Sciences. 2020;30(186):163-9.

35. Rodd ZA, Gryszowka VE, Toalston JE, Oster SM, Ji D, Bell RL, et al. The reinforcing actions of a serotonin-3 receptor agonist within the ventral tegmental area: evidence for subregional and genetic differences and involvement of dopamine neurons. Journal of Pharmacology and Experimental Therapeutics. 2007;321(3):1003-12. 
36. Figee $M$, Vink M, de Geus F, Vulink N, Veltman DJ, Westenberg $H$, et al. Dysfunctional reward circuitry in obsessive-compulsive disorder. Biological psychiatry. 2011;69(9):867-74.

37. Meneses A. 5-HT system and cognition. Neuroscience \& Biobehavioral Reviews. 1999;23(8):111125.

38. Stahl SM. Mechanism of action of serotonin selective reuptake inhibitors: serotonin receptors and pathways mediate therapeutic effects and side effects. Journal of affective disorders. 1998;51(3):215-35.

39. Bloch M, Landeros-Weisenberger A, Kelmendi B, Coric V, Bracken M, Leckman J. A systematic review: antipsychotic augmentation with treatment refractory obsessive-compulsive disorder. Molecular psychiatry. 2006;11(7):622-32.

40. Dold M, Aigner M, Lanzenberger R, Kasper S. Antipsychotic augmentation of serotonin reuptake inhibitors in treatment-resistant obsessive-compulsive disorder: a meta-analysis of double-blind, randomized, placebo-controlled trials. International Journal of Neuropsychopharmacology. 2013;16(3):557-74.

41. Hadi F, Kashefinejad S, Kamalzadeh L, Hoobehfekr S, Shalbafan M. Glutamatergic medications as adjunctive therapy for moderate to severe obsessive-compulsive disorder in adults: a systematic review and meta-analysis. BMC Pharmacology and Toxicology. 2021 2021/11/04;22(1):69.

\section{Figures}

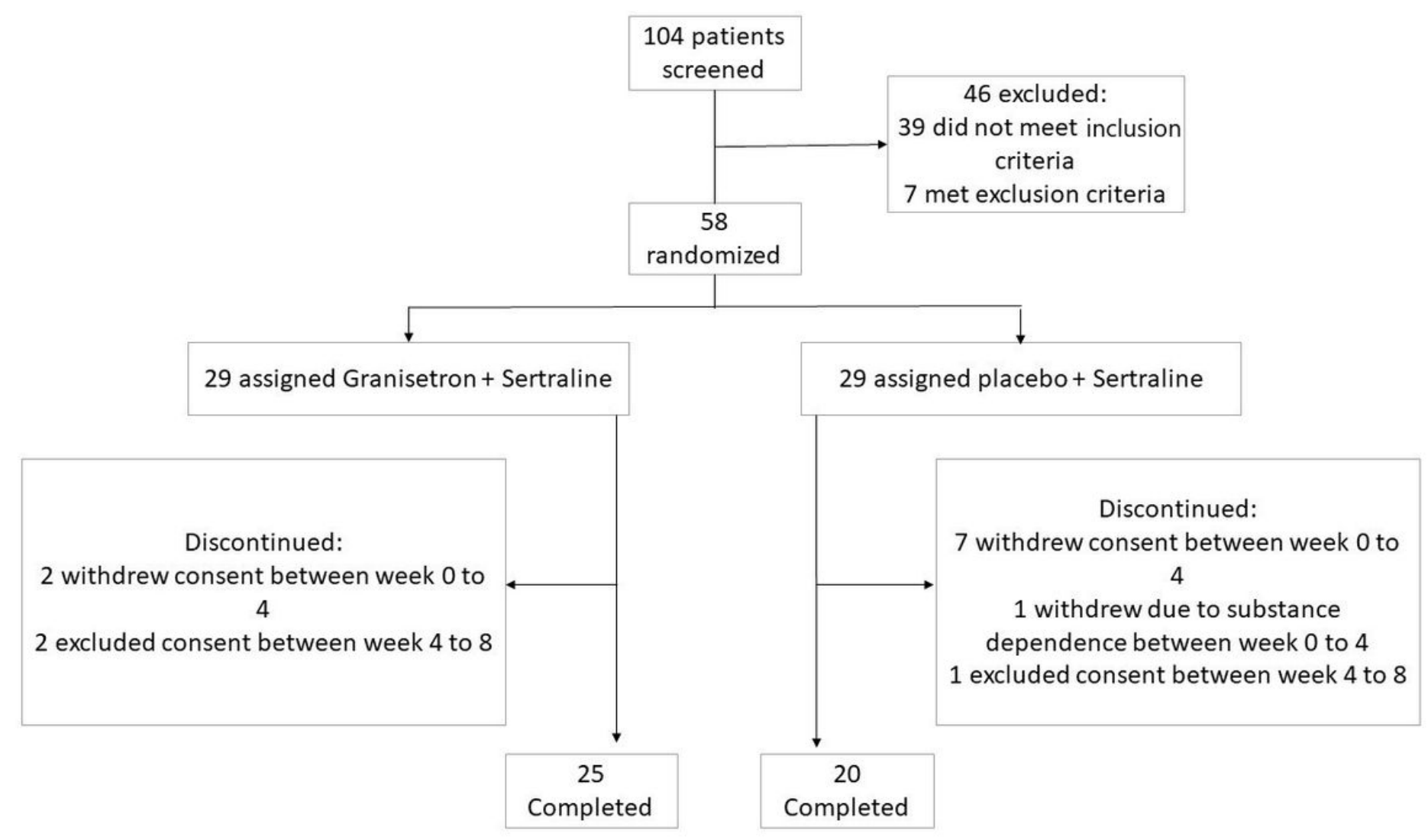

Figure 1 
Trial participants' flow-diagram.

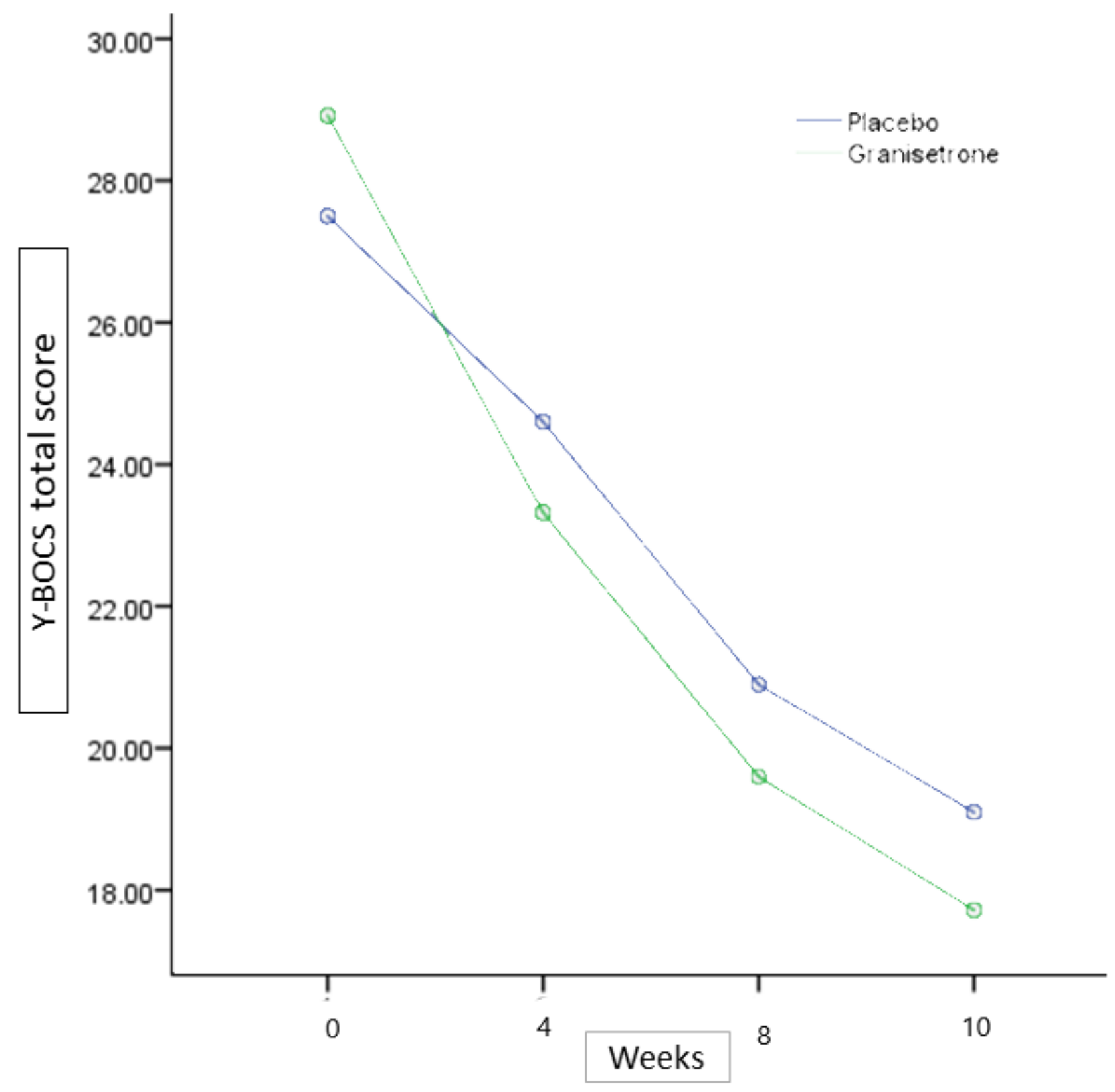

Figure 2

Yale-Brown Obsessive-Compulsive Scale (Y-BOCS) total score trend for each group during the trial course 


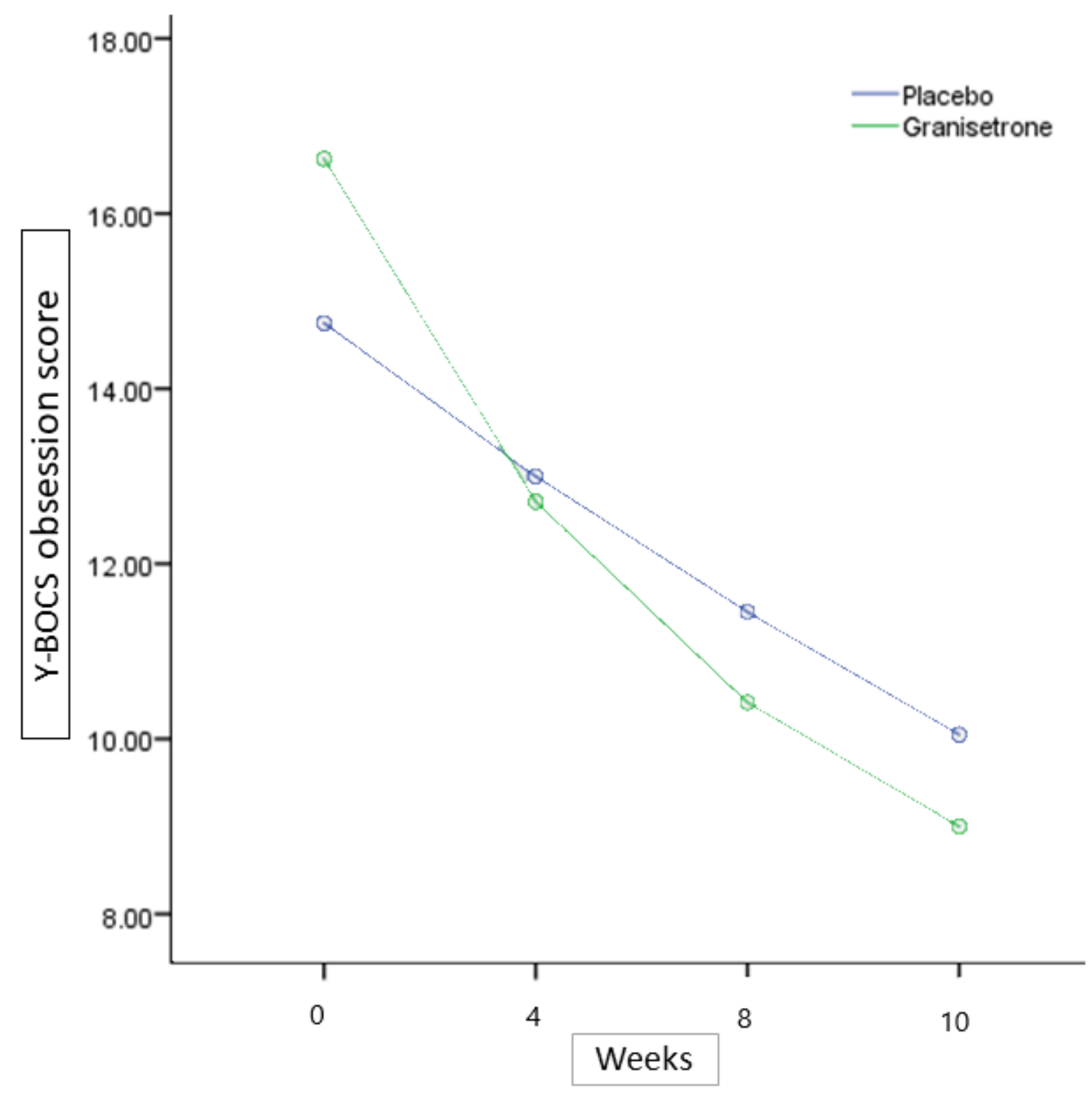

Figure 3

Yale-Brown Obsessive-Compulsive Scale (Y-BOCS) obsession subscale score trend for each group during the trial course 


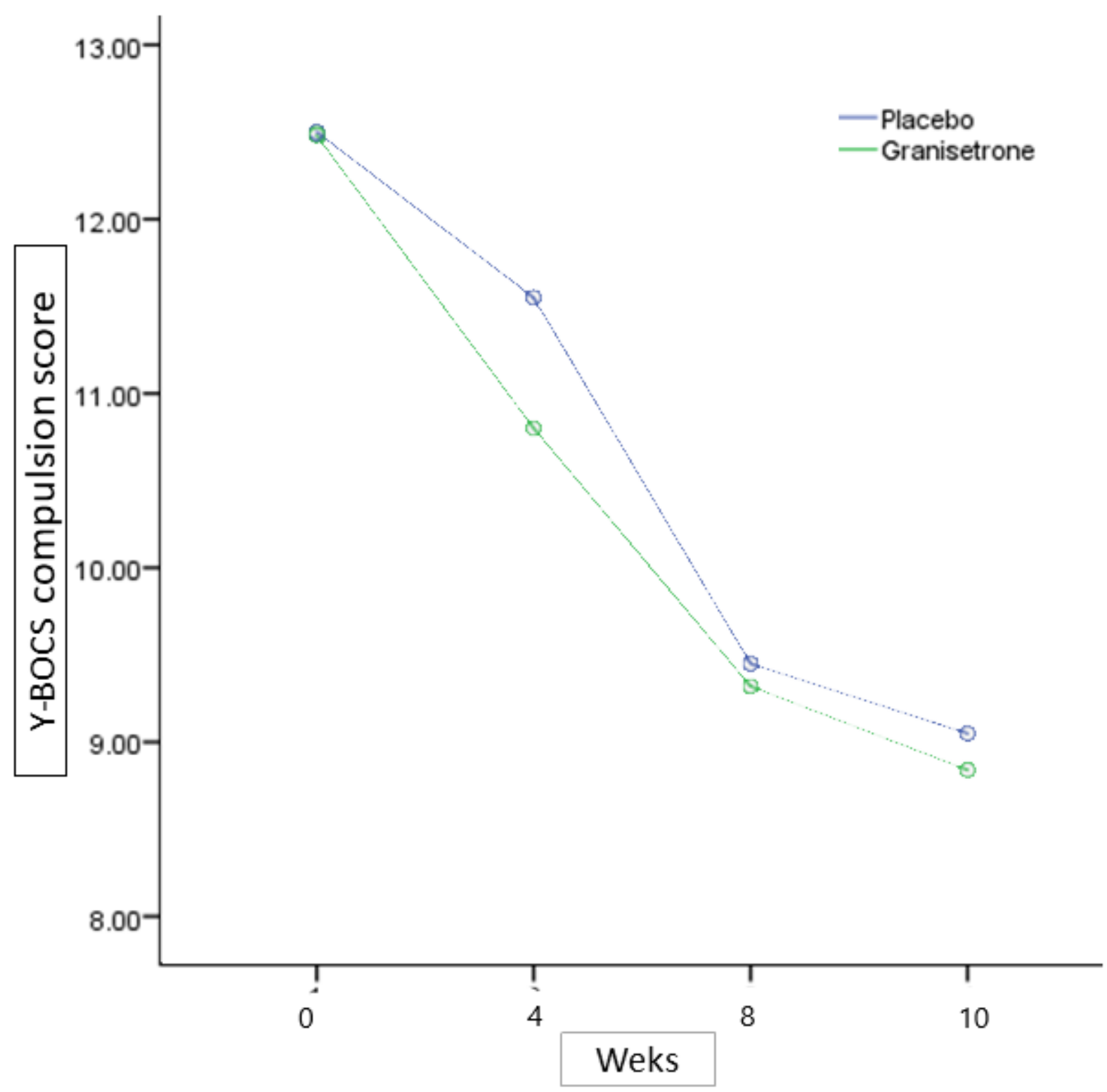

Figure 4

Yale-Brown Obsessive-Compulsive Scale (Y-BOCS) compulsion subscale score trend for each group during the trial course 